\title{
High Strain Rate Indentation-Induced Deformation in Alumina Ceramics Measured by $\mathrm{Cr}^{3+}$ Fluorescence Mapping
}

C.E.J. Dancer ${ }^{1 *}$, H.M. Curtis ${ }^{1}$, S.M. Bennett ${ }^{1}$, N. Petrinic $^{2}$, R.I. Todd $^{1}$

1 Department of Materials, University of Oxford, Parks Road, Oxford, OX1 3PH, UK

2 Department of Engineering Science, University of Oxford, Parks Road, Oxford, OX1 3PJ, UK

* Corresponding Author. Email claire.dancer@materials.ox.ac.uk , Tel. +44(0)1865 273787 Fax. +44(0)1865 273789

Keywords: Armour; $\mathrm{Al}_{2} \mathrm{O}_{3}$; Mechanical Properties; Plasticity; Residual Stress

\begin{abstract}
Alumina materials with a range of grain sizes and purities were subjected to small-scale dynamic impact by sharpened tungsten carbide projectiles at sub-ballistic velocities. The resistance of the materials to fracture was recorded by visual examination of the cracking on the impacted surface and the damage in the subsurface region. The residual stress and plastic deformation induced in each material were examined using $\mathrm{Cr}^{3+}$ fluorescence mapping. A modified Hertzian indentation model of the stress state in the material with the addition of a blister field representing the stress induced by the presence of the subsurface plastic zone was found accurately describe the observed cracks beneath the surface of the material, as well as the radial cracks on the surface.
\end{abstract}

\section{Introduction}


Alumina has been used as an armour material since the 1970s [1,2] because it has low density, can be produced by inexpensive processing methods and is sufficiently durable to defeat many types of incoming projectile $[3,4]$. Alumina tiles are able to defeat these by a number of mechanisms including shattering or blunting the projectile, and dissipation of the energy of the projectile by the cracking and/or plastic deformation of the ceramic. In addition, comminuted material can erode the projectile, reducing it in size or completely destroying it $[5,6]$.

Alumina has been extensively studied by a variety of high strain rate tests to assess its performance as an armour material [7-9]. However the possibility of investigating material response at a microstructural scale following tests carried out at ballistic velocities is generally limited due to the destructive nature of the tests. The complicated processes involved make it difficult to correlate individual quasi-static measures of material properties such as fracture strength or toughness to the behaviour of the material under dynamic conditions [10]. Tests are also often limited to a small number of materials, and so it is difficult to correlate material characteristics of alumina such as purity, grain size and density with performance under dynamic impact. Anderson et al. [11] conclude from tests on alumina samples with 3 different grain sizes that samples with a smaller grain size have superior resistance to impact by tungsten carbide spheres at velocities between 10-70 m/s. For these velocities there is no discernible rate dependence on the level of damage sustained, although the size of the impact crater increases with impact velocity, as would be expected from analogy with quasi-static indentation since the effective load on the specimen increases with the impact velocity. Lankford [12] demonstrated that a significant increase in compressive strength occurs only above a certain critical strain rate, measured as $>10^{3} \mathrm{~s}^{-1}$ for $\mathrm{Al}_{2} \mathrm{O}_{3}$ samples with a grain size of $25 \mu \mathrm{m}$. 
Material behaviour during indentation tests made under quasi-static conditions (described by Lawn and Wilshaw [13]) does not correlate well with performance under dynamic conditions. In dynamic impact, failure is caused by the coalescence of many microfractures which are activated at high strain rates [14] to accommodate the strains generated by plastic deformation [15]. Lankford et al. [16] attribute the extent of plastic deformation achievable prior to failure to the pre-existing flaw population (e.g. pores and glassy grain boundaries) in the alumina specimen. Alumina specimens show elastic or inelastic responses to dynamic impact, depending on the velocity of impact and the microstructure of the specimen [15].

For quasi-static indentations, the position and width of $\mathrm{Cr}^{3+}$ luminescence peaks in alumina can be related to the residual stress and the extent of plastic deformation in the ceramic respectively $[17,18]$, providing the background stress field does not vary over the collection volume. This condition is met for materials, such as those studied here, where the magnitudes of any residual stresses present in the as-sintered material (before any deformation has been carried out) do not vary significantly between randomly chosen points on a sample, so that the measured change in $\mathrm{Cr}^{3+} \mathrm{R} 1$ peak position in the indented specimen is due solely to the indentation made by indenter. By collecting spectra at points across the sample surface this technique has previously been used to study the deformation caused by quasi-static indentations $[17,19]$. This work extends the technique to the study of indentations produced by a sub-ballistic velocity dynamic impact test. Using a sub-ballistic velocity (c. $100 \mathrm{~m} / \mathrm{s}$ rather than c. $700-800 \mathrm{~m} / \mathrm{s}$ for a ballistic test [3]) allows recovery of intact specimens so that the deformation processes which occur during impact can be studied and compared with models for quasi-static indentations. In addition, the tests in this work use a projectile with similar shape and material to armour piercing bullets, rather than, for example, the welldefined sharp Vickers indenter or blunt spherical Hertzian indenter. This allows the results of 
this work to be directly compared to the effects of ballistic impact on alumina materials, such that damage processes characteristic of the indenter shape but not necessarily of the impact velocity can be determined.

\section{Experimental Methods}

Alumina discs were produced using either TM-DAR powder (Tai-Mei, 99.99\% purity, 100 $\mathrm{nm}$ particle size) or AES11c powder (Sumitomo, 99.9\% purity, $500 \mathrm{~nm}$ particle size). For two TM-DAR specimens $0.25 \mathrm{wt} . \% \mathrm{MgO}$ to inhibit grain growth and $2.1 \mathrm{wt} \%$ of organic dispersant (Dispex A40, Allied Colloids) were added to the alumina powder and mixed by attrition milling in water (Szegvari 01HD attrition mill, yttria-stabilized zirconia tank and blade and $3 \mathrm{~mm}$ diameter zirconia balls) for $2 \mathrm{~h}$. Powders were freeze-dried and calcined for $1 \mathrm{~h}$ at $600{ }^{\circ} \mathrm{C}$ to remove the dispersant before uniaxial pressing at $54 \mathrm{MPa}$ and sintering at $1550^{\circ} \mathrm{C}$ for $2 \mathrm{~h}$ in air (A) or vacuum (B). A third TM-DAR specimen (C) and the AES11c samples $(\mathrm{F})$ were produced from the as-purchased powders after uniaxial pressing at $54 \mathrm{MPa}$ and sintering in air at $1550^{\circ} \mathrm{C}$ for $2 \mathrm{~h}$. The AES11c samples (F) were additionally coldisostatically pressed at $150 \mathrm{MPa}$ between the uniaxial pressing and sintering stages. Following sintering the discs were all approximately $25 \mathrm{~mm}$ in diameter and $5 \mathrm{~mm}$ in thickness. In addition similar discs of two debased alumina materials were provided by Morgan Technical Ceramics. These contained approximately 5\% (D) and 2\% (E) glassy phase, and were studied to provide a contrast to the much purer TM-DAR and AES11c samples (for which no glassy phase was visible in SEM micrographs), in order that the effects of both grain size and glass content could be compared to impact behaviour. At least 3 specimens of each type were tested under impact. The grain size was measured from SEM images (JEOL 6300 and Carl Zeiss EVO LS15) of a polished and thermally etched crosssection of each sample using the linear intercept method with a geometric multiplying factor 
of 1.56 . The density was measured by the Archimedes method using distilled water. A summary of the processing conditions and microstructural characteristics of the samples used in this work is given in Table 1.

Prior to high strain rate and quasi-static impact testing, the surfaces of the discs were lapped and polished to a $3 \mu \mathrm{m}$ finish using diamond pastes. This was required to minimise noise in the optical fluorescence spectra obtained after impact testing.

High strain rate impact tests were carried out by firing sharpened projectiles at polished ceramic discs using a gas gun (Fig. 1). Tungsten carbide cermet (Tungstcarb products, grade K20, $3 \mathrm{~mm}$ diameter) rods were sharpened using a diamond-coated glass engraving tool to produce sharp projectiles similar to the cores of armour piercing bullets. Projectiles had an average mass of $0.46 \mathrm{~g}$ and tip angle of $45^{\circ}$. Tip sharpness was measured using 3D optical microscopy (Alicona InfiniteFocus) (Fig. 2) and projectiles were rejected if the tip diameter was greater than $200 \mu \mathrm{m}$. The average diameter of the tip was c.100 $\mu \mathrm{m}$, measured from 3D optical micrographs. All alumina discs were glued (UHU all-purpose glue) to a thick backing disc of alumina to avoid failure by bending at the back surface and mounted to a steel bar of similar diameter to the samples using a small amount of vacuum grease. The sharpened tungsten carbide projectile was attached to a nylon sabot and fired towards the samples over a distance of approximately $2 \mathrm{~m}$ using the gas gun. The sabot and the projectile were separated before impact by means of a splitter. The velocity was measured using light gates and was adjusted by control of the gas pressure to approximately $100 \mathrm{~m} / \mathrm{s}$. Tests were filmed using a high speed camera (Phantom 7, Vision Research, USA).

Following impact the craters on specimens were examined by scanning electron microscopy (JSM6300, tungsten filament and Carl Zeiss EVO LS15, LaB 6 filament). The indentation volume was measured using a 3D optical microscope (Alicona InfiniteFocus) in "cutting plane mode". An average position of the surface height around the indentation was 
recorded and the volume of the void below this depth was measured, subtracting where necessary the volume of any material protruding above the surface level. The surface level (the "cutting plane") was measured at some distance away from the indentation.

$\mathrm{Cr}^{3+}$ fluorescence peak positions were mapped as a function of position on the face of the specimens using a 1000 series Renishaw Raman microscope with a 50mW He-Ne laser and an automated $\mathrm{X}-\mathrm{Y}-\mathrm{Z}$ stage (Prior, UK). To determine the unstrained reference peak characteristics, spectra were taken at four points on the sample far from the impact site and the measured peak positions and widths averaged. All images were taken with non-confocal settings using a 50x objective lens with a numerical aperture of 0.75 and working distance of $370 \mu \mathrm{m}$. Spectra were acquired from the surface of the specimen including the crater region every $50 \mu \mathrm{m}$ in $\mathrm{X}$ and $\mathrm{Y}$ directions and fitted using GRAMS/32 software (Galactic Industries Corporation, UK). Samples were then cross-sectioned through the indentation region, polished and examined by fluorescence microscopy and SEM.

\section{Results}

\subsection{Macroscopic observations of damage to alumina specimens after impact}

The majority of the alumina samples survived the projectile impact intact, though with visible marks to the disc surface at the impact site and radial cracks spreading from this point. A few specimens suffered complete fracture. A qualitative analysis of the extent of surface damage based on the average number of radial cracks per specimen and the incidence of complete fracture, allowed the materials to be ranked by performance (Table 2). It is clear that the best performance on this basis was for non-glassy alumina samples. For each sample type, 3 or more discs were tested with a reasonably high degree of reproducibility. It was difficult to distinguish between the performances of the three TM-DAR-type specimens (A, B and C) which all showed a very similar response to impact. While the measured projectile velocity 
varied between $76-121 \mathrm{~m} / \mathrm{s}$, with an average of $101 \mathrm{~m} / \mathrm{s}$, no systematic variation in performance with velocity was observed.

\subsection{Microscopic observations of damage to alumina specimens after impact}

The impact sites of intact specimens were examined by 3D optical microscopy and the surface profiles recorded to assess the diameter, depth and volume of the impact crater (Fig. 3). The alumina samples with essentially zero glass content (A-C and F) have relatively flat impact sites with maximum depth of approximately $10 \mu \mathrm{m}$ and average diameter around 1.3 mm. The glassy specimens D and E had cone-shaped impact sites, with depth of 15-40 $\mu \mathrm{m}$ and diameter around $1.6 \mathrm{~mm}$. The diameter was measured from a number of profiles taken across the impact zone, and was taken to be the region where the roughness increased, as this agreed with the visual observation of the indentation mark. The depth was taken as the deepest point across the profile within this region. These measurements therefore have some uncertainty, being based on visual inspection, and also it was not possible to assess whether the volume change was due solely to the indentation, or whether material had additionally been lost as ejected fragments at the indentation site. It was not possible to determine a general relationship between crater depth and material properties for this number of samples. It is noted that these indentation sites are much larger in diameter than typical quasi-static indentations in similar materials [19].

Micro-cracks following some of the grain boundaries were observed using SEM on the surfaces of all samples around the indentation site (Fig. 4). This area of the surface containing micro-cracks is therefore described in this paper as the "surface micro-cracked zone". The equiaxed regions between micro-cracks are larger than the grain size. The outer edge of the surface micro-cracked zone corresponds to the start of radial cracks in whole 
specimens. The outer diameter of the surface micro-cracked zone was fairly similar for all materials at around 0.75-1.5 mm, and these are indicated as a dotted circle in Fig. 3.

Samples were cross-sectioned through the impact site and polished to reveal the cracks and plastic zone around the impacted region (Fig. 5). Comparison of Fig. 3 and Fig. 5 demonstrates that this sub-surface pullout zone has significantly smaller diameter than the observed surface micro-cracked zone in these specimens, i.e. the surface micro-cracked zone does not extend into the bulk of the material. Glassy materials (D and E) showed larger pullout zones than samples A-C and F. Cracks running roughly perpendicular to the surface and below the pullout zone, and lateral cracks which run parallel to the surface were observed in all specimens. Fig. 5a (for A) and Fig. 5c (for C) show cracks which change path direction from approximately perpendicular to a lateral path. The impact site for sample F (Fig. 5f) was spread over a wider area compared to the other materials and appears in this cross-section to consist of two separate regions with associated cracks underneath which link together. This may be due the projectile breaking into 2 or more large pieces during impact, but this could not be verified from the high speed video due to the limitations of the camera angle and the frame rate. Chips of material were missing from this cross-section; this is believed to have occurred during sectioning as a result of cracking induced during impact. Some cracks were observed in intact specimens (e.g. Fig. 5d) at around $80^{\circ}$ to the surface.

\section{3 $\mathrm{Cr}^{3+}$ fluorescence mapping of plastic deformation and residual stresses}

$\mathrm{Cr}^{3+}$ fluorescence maps of impact sites (Fig. 6 and Fig. 7) for representative intact samples of each type show a number of common features. In Fig. 6, a region of compressive residual stress (negative peak position shifts) at the impact site relaxes towards the neutral peak position of the bulk of the specimen such that a representation diameter for the region containing significant residual stress can be estimated. This corresponds approximately to the 
observed diameter of the micro-cracked zone observed by 3D optical microscopy (Fig. 3). Small tensile (positive position shift) regions are observed which correspond to the tips of radial cracks or other damage to the specimen. The diameter of the compressive zone is similar for all the specimens produced from TM-DAR powder and these are smaller than the compressive zones in the glassy materials D and E. However it is noticeable that the AES11c alumina sample $\mathrm{F}$ has a much larger compressive zone than specimens $\mathrm{A}$ and $\mathrm{B}$ (which have similar grain sizes to F), so clearly average grain size is not the only contributing factor. Peak position shifts range from -5 to $+1 \mathrm{~cm}^{-1}$. This corresponds to a hydrostatic stress $\sigma_{H}$ range of 659 to $+132 \mathrm{MPa}$ calculated from:

$\Delta v_{\mathrm{R} 1}=\Pi_{H} \sigma_{H}$

where $\Pi_{H}$ is the hydrostatic piezospectroscopic coefficient, taken as $7.59 \mathrm{~cm}^{-1} \mathrm{GPa}^{-1}$ for a polycrystal with grain size smaller than the sampling volume, as in this case [20]. By comparing Fig. 6a with Fig. 6b-f it is clear that the zero peak shift position is reached much closer to the indentation for specimen A than for the other specimens.

The width change images (Fig. 7) indicate fewer differences between samples than the position change maps. The impact region appears smaller, as the width change records the size of the plastically deformed zone, rather than the larger zone affected by the residual stress given by the position maps which includes also the region deformed only elastically. This is in agreement with observations by microscopy (Fig. 3 and Fig. 5). Specimen type F shows a larger plastic zone than the other specimens examined, with a larger total area and more numerous regions of significant broadening. In addition, sample type D shows a very intense peak broadened region at the centre of the impact region.

As well as making the $\mathrm{Cr}^{3+}$ fluorescence measurements on the top surface, samples were also cross-sectioned through the indented region and polished so that the deformation within the material could be studied. Fig. 8 and Fig. 9 are the maps of the $\mathrm{Cr}^{3+}$ fluorescence 
peak position and width respectively for these cross-sections from the same specimens as shown in Fig. 5-7. In some cases specimens were lost during sectioning as they fractured along existing cracks. Direct quantitative comparison with Fig. 6 and Fig. 7 for the top surface is not appropriate as significant stress relaxation would be expected during sectioning. The region immediately below the indentation generally shows the largest tensile stress, which reduces with distance from the indentation into the specimen eventually becoming compressive (Fig. 8). The broadened zones observed in Fig. 9 correspond directly to the sub-surface pullout-zones observed in the SEM micrographs in Fig. 5. Greater peak broadening, and to a greater depth, is observed for the two glassy materials (specimens D and E in Fig. 9d-e).

\section{Discussion}

\subsection{Deformation Processes Occurring in the Material}

The cracks and deformed regions observed in these alumina discs are due to the stress states occurring during the dynamic impact experiment. Two widely used models for stress states during quasi-static indentation are the Hertzian stress field equations for blunt indenters $[21,22]$ and Yoffe's model [23] for sharp indenters. The latter combines the Boussinesq field (a limiting case of the Hertzian equations for a sharp indenter point) with a blister field (a mathematical representation of a hemispherical inclusion consisting of two outward double forces in the surface plane and an inward double force normal to the surface, such that the surface is free of stress) [23]. The blister field represents the plastic zone known to occur beneath quasi-static sharp indenters [24].

In this work, from the evidence of $\mathrm{Cr}^{3+}$ fluorescence mapping, it is clear that a plastic zone is present below the surface area which was impacted by the projectile. Plasticityinduced micro-cracks observed in the cross-sectional images of the indented samples (Fig. 5) 
lead to more significant pullout than in areas that have not been plastically deformed, and for Vickers hardness indentations, such intense micro-cracking has been shown to be nucleated only beneath the indenter [24]. Significant $\mathrm{Cr}^{3+}$ fluorescence $\mathrm{R} 1$ peak broadening was seen in this region of the indents studied here (Fig. 9), indicating that a variety of stress states exists within this zone because of the stress fields of dislocations and twins, and that plastic deformation is also responsible for the micro-cracks in the present case $[17,19]$. The minimal broadening outside this volume indicates that negligible plastic deformation takes place elsewhere. This region of enhanced subsurface micro-cracking and pullout will therefore be described from here as the plastic zone.

While the projectiles used had sharpened points, there are several reasons why the indenter shape is more accurately approximated by the Hertzian equations for blunt indenters than by the Yoffe model for sharp indenters. First, as discussed earlier, it is clear from 3D optical microscopy of the projectiles prior to testing that the tips of the projectiles were somewhat blunted, having an average diameter c. $100 \mu \mathrm{m}$. High speed photography (not shown) of the moment of impact suggests some blunting occurs to the projectile tip during impact prior to projectile fracture, however the extent of this could not be determined due to the low resolution of the high speed camera images. In addition, lower values of fluorescence peak broadening were recorded in these dynamic indentations (Fig. 7 and Fig. 9) compared to static Vickers indentations [19], as would be expected for quasi-static indentations made using spherical or flat-ended cylindrical Hertzian indenters compared to those from sharp pyramidal Vickers indenters.

The experimental observations described above suggest that the most appropriate model for the stress states created by the impact of these projectiles on alumina tiles is the combination of the Hertzian equations (representing the effect of the blunt indenter) with a blister field (representing the effects of the plastic zone). The equations for this model (Eq. 2- 
5) were determined by combining the stress due to the blister field with the standard Hertzian equations after Feng et al. [25], but assuming a hemispherical plastic zone, and using cylindrical polar coordinates.

$\sigma_{r}=$

$\frac{3 P}{2 \pi a^{2}}\left\{\frac{1-2 v}{3} \frac{a^{2}}{r^{2}}\left[1-\left(\frac{z}{u^{1 / 2}}\right)^{3}\right]+\left(\frac{z}{u^{1 / 2}}\right)^{3} \frac{a^{2} u}{u^{2}+a^{2} z^{2}}+\frac{z}{u^{1 / 2}}\left[u \frac{1-v}{a^{2}+u}+(1+v) \frac{u^{1 / 2}}{a} \tan ^{-1}\left(\frac{a}{u^{1 / 2}}\right)-\right.\right.$

$2]\}+\frac{2 B}{R^{3}}\left[2(1-2 v)-\frac{3}{R^{2}}\left(z^{2}(1-2 v)+2 r^{2}(1-v)-\frac{15 z^{2} r^{2}}{R^{2}}\right)\right]$

$\sigma_{\phi}=-\frac{3 P}{2 \pi a^{2}}\left\{\frac{1-2 v}{3} \frac{a^{2}}{r^{2}}\left[1-\left(\frac{z}{u^{1 / 2}}\right)^{3}\right]+\frac{z}{u^{1 / 2}}\left[2 v+u \frac{1-v}{a^{2}+u}-(1+v) \frac{u^{1 / 2}}{a} \tan ^{-1}\left(\frac{a}{u^{1 / 2}}\right)\right]\right\}+$

$\frac{2 B}{R^{3}}(1-2 v)\left[2-\frac{3 z^{2}}{R^{2}}\right]$

$\sigma_{z}=-\frac{3 P}{2 \pi a^{2}}\left(\frac{z}{u^{1 / 2}}\right)^{3} \frac{a^{2} u}{u^{2}+a^{2} z^{2}}+\frac{6 B z^{2}}{R^{5}}\left[\frac{5 z^{2}}{R^{2}}-3\right]$

$\tau_{r z}=-\frac{3 P}{2 \pi a^{2}}\left(\frac{r z^{2}}{u^{2}+a^{2} z^{2}}\right)\left(\frac{a^{2} u^{1 / 2}}{a^{2}+u}\right)-\frac{6 B r z}{R^{5}}\left[2-\frac{5 z^{2}}{R^{2}}\right]$

$\sigma_{r}$ represents the normal stress component for the radial direction, $\sigma_{z}$ that in the axial direction normal to the surface and $\sigma_{\phi}$ that in the hoop direction $\tau_{r z}$ is the $r-z$ shear component. $r$ and $z$ are the radial and axial distances respectively measured from the centre of the indentation on the surface. $R=\sqrt{r^{2}+z^{2}}$ and $u=\frac{1}{2}\left[\left(r^{2}+z^{2}-a^{2}\right)+\sqrt{\left(r^{2}+z^{2}-a^{2}\right)^{2}+4 a^{2} z^{2}}\right]$. a is the radius of the contact area in the case of purely elastic contact. The contacts between the projectiles and the surfaces were not purely elastic but, as an approximation, the contact zones from Fig. 3 were used to provide an estimate of the value for $a$ in Eqs 2-5. The form and magnitude of this combined stress field are controlled by $P$, the load applied at the ceramics surface by the projectile, and by $B$, a parameter related to volume of the plastic indentation made by the projectile. 


\subsubsection{Stress States beneath the Surface}

The stress fields in cross section ( $r$ - $z$ plane) were calculated for comparison to experimental data to assess whether or not the equations correctly predict the position and orientation of the observed cracks. The maximum principal stress $\sigma_{1}$ in this $r-z$ plane and the direction $\omega_{c}$ relative to the surface at which a crack would be expected to propagate (orthogonal to the direction of $\sigma_{1}$ ) were calculated for positive $r$ and $z$ from Eqs 2-5:

$$
\begin{gathered}
\sigma_{1}=\frac{\sigma_{r}+\sigma_{z}}{2}+\sqrt{\left(\frac{\sigma_{r}-\sigma_{z}}{2}\right)^{2}+\sigma_{r z}^{2}} \\
\tan \omega_{c}=\frac{\sigma_{r}-\sigma_{z}}{2 \tau_{r z}}+\sqrt{\left(\frac{\sigma_{r}-\sigma_{z}}{2 \tau_{r z}}\right)^{2}+1}
\end{gathered}
$$

It has been previously demonstrated (for example by Fischer-Cripps [28]) that without the blister field to represent the plastic zone (i.e. $B=0$ ), the Hertzian indentation equations result in a maximum tensile principal stress $\sigma_{1}$ just beyond the edge of the contact area, with an initial crack direction of $22-24^{\circ}$ [28]. This stress results in a cone crack at this relatively shallow angle to the surface, as has been experimentally observed (see, for example, Roesler [29] for soda lime glass).

For $B>0$, three regimes of behaviour exist, with the expected stress field changing depending on the relative magnitude of $P$ and $B$ in Eqs 2-5. For $P \gg B$ i.e. $B / P \approx 0$, the Hertzian field terms are dominate the stress field (Eqs 2-5), and the maximum tensile principal stress lies at the surface just outside the plastic zone as described above. When $P$ and $B$ are relatively similar in magnitude $(B / P \approx 1)$, the blister field terms dominate and the maximum tensile principal stress lies immediately beneath the plastic zone and acts at $90^{\circ}$ to the surface. However, at intermediate values of $0.02<B / P<0.05$ the stress field changes significantly as the magnitude of the two stress field terms is similar. The position of the maximum tensile principal stress (Fig. 10a) is found to lie on the edge of the plastic zone at a position between those described above, and the expected crack propagation direction in this 
region is $60-90^{\circ}$, depending on the exact position of crack initiation (Fig. 10b). This is consistent with the various orientations of the cracks observed below the indentations in the non-glassy and glassy samples respectively (Fig. 5).

By considering the kinetic energy of an impact event, Tirupataiah and Sundararajan [26] give an equation which may be used to predict the load exerted on the target from the measured volume of the indentation:

$P=H_{d} \pi a^{2}=\frac{m u_{i}^{2}}{2 \Delta V} \pi a^{2}$

where $H_{d}$ is the dynamic hardness, $m$ is the mass of the projectile, $u_{i}$ is the velocity of the projectile before impact, $a$ is the contact radius, taken as the radius of the indentation mark on the surface, and $\Delta V$ is the change in volume (measured experimentally, Fig. 3). For the samples studied in this work, Eq. 8 gives loads of 0.1-86 MN. The value of the coefficient $B$ can be calculated from Eq. 9 [27]:

$B=\frac{6}{5 \pi} E \cdot \Delta V$

where $E$ is the Young's Modulus of the material and $\Delta V$ is the volume of the indentation, which is measured experimentally here but subject to errors as discussed earlier. $B$ is calculated to be around $0.01-0.02 \mathrm{~Pa} \mathrm{~m}^{3}$ for all the specimens of the pure alumina materials (A-C and F) and between 0.2-1.0 $\mathrm{Pa} \mathrm{m}^{3}$ for the specimens of the commercial materials (D and E). These values of $B$ and $P$ gave $B / P$ ratios of $0.0001-0.0006 \mathrm{~m}^{3}$ for types $\mathrm{A}-\mathrm{C}$ and $\mathrm{F}$ and 0.5-8.7 $\mathrm{m}^{3}$ for types $\mathrm{D}$ and $\mathrm{E}$. We therefore expect that the pure alumina samples (A-C and $\mathrm{F}$ ) are more likely to contain cone cracks initiating from the surface near the plastic zone, while the commercial materials (D and E) are likely to contain cracks beneath the plastic zone at $90^{\circ}$ to the surface. This broadly agrees with the observations of the indentation regions in Fig. 5.

More precise prediction of the crack patterns is not possible because several assumptions have been made in the analysis, and the experimentally measured parameters are 
also subject to errors. By estimating the load from Eq. 8, we assume that all of the kinetic energy of the projectile is used to create the indent cavity. This is unlikely to be correct in this case as there are other energy-consuming processes occurring such as the deformation of the projectile, and other damage to the sample. Additionally, the dynamic hardness is converted to a load by using the contact area of the indentation; this implies that the indentation is of a regular shape such that the surface area is proportional to the volume. It can be seen from Fig. 3 that this is not the case here, as while the surface areas of the indentations in different samples are relatively similar, their volumes vary considerably. Therefore the actual load is expected to be some fraction of that which may be calculated from Eq. 8; the accurate measurement of the load exerted on the sample during impact is the subject of ongoing research.

Upon unloading when $P=0$, the stress distribution is solely determined by the blister field terms in Eq. 2-5. Therefore the directions and magnitudes of the principal stresses change leading to existing crack paths changing direction. This is in agreement with, for example, Fig. $5 \mathrm{c}$ where the cracks below the plastic zone propagate at approximately $90^{\circ}$ to the surface before changing to a lateral direction. The change in crack paths due to changing stress states has been previously observed by Yoffe theoretically [23] and Marshall et al. experimentally [30].

\subsubsection{Stress States in the Surface}

Two cracking patterns were observed in the surface of the alumina discs: a surface microcracked zone around the impact site (Fig. 4) and, in most cases, radial cracks originating from the edge of the micro-cracked zone (e.g. Fig. 3d). The surface micro-cracked zone is larger in radius than the sub-surface plastic zone and therefore does not experience plastic deformation except within the sub-surface plastic zone diameter (Fig. 7). This micro-cracking is confined 
to the surface where the flaw concentration is higher compared to the bulk. We therefore suggest that the observed surface micro-cracking seen in Fig. 4 is not due to plastic deformation but occurs because the surface is under sufficient biaxial tensile stress to nucleate micro-cracks at existing flaws and there is a sufficient flaw distribution to allow significant micro-cracking. Therefore both the micro-cracked region and the radial cracks can also be compared to Eqs 2-5 to examine the stress states existing in the samples during deformation. From Eqs 2-5 it can be simply shown that at any point in the surface, the principal stresses in the surface $\sigma_{r}$ and $\sigma_{\phi}$ have opposite signs for all combinations of $B$ and $P$ where $B, P \geq 0$, so that one or the other principal stress will be tensile, but not both.

The radial cracking (Fig. 3d) observed can therefore be simply explained by the presence of a tensile (positive) radial stress $\sigma_{r}$ in the surface during and/or after the deformation process, corresponding with $\sigma_{\phi}$ being compressive (negative). However, the stress state in the surface from Eqs 2-5 cannot account for the observed micro-cracking patterns, as it would require that the micro-cracks were formed in two discrete events involving stress reversal. We would then expect to find long continuous cracks in the direction of initial formation and a second set of cracks formed subsequently at $90^{\circ}$ to the first set, and showing discontinuities at these first set of cracks. It is clear from Fig. 4 that this is not the case as cracking appears equivalent in all directions and there is no evidence of the crack discontinuities described. Therefore the observed micro-cracking must be caused either by changes in the local stress state once cracking and/or plasticity have commenced, such that the biaxial tensile stress can exist in the surface, or by a dynamic effect not accounted for in the quasi-static models (Eqs 2-5). The latter argument is supported by the fact that such zones of equiaxed surface micro-cracking have not been reported in quasi-static tests. Cracking has been shown to substantially modify the strain around static indentations [19]. 


\subsection{Microstructural Effects on Performance under Impact}

The classical models for quasi-static indentation by blunt and sharp indenters described above do not take account of the variation in microstructure of the materials tested. This set of alumina specimens was made using a range of starting powders and processing routes, and therefore differ in their grain sizes and glass contents (Table 1). The largest degree of plasticity, measured from the $\mathrm{Cr}^{3+}$ fluorescence measurements (Fig. 7 and 9) was observed in the sample with the largest glass content (D). This may be because the presence of the glass phase at the grain boundaries reduces the constraint between adjacent grains, allowing a greater degree of plasticity before fracture. The best overall performance, assessed as being that of the samples with the least observed surface damage (Table 2), was for sample type F which was produced from a lower purity alumina powder compared to A-C and had a wide grain size distribution with average grain size of $2 \mu \mathrm{m}$. The large grain size distribution may be responsible for the increased resistance to fracture observed in these samples due to the presence of some extremely small grains. However it should also be noted that sample type F were the only samples which were cold isostatically pressed before sintering, which may affect the resistance to fracture. It is clear that the microstructure of the alumina affects its performance under impact, and the development of models which take account of these microstructural variations is the subject of our ongoing research.

\section{Conclusions}

We have studied the response of a range of alumina materials to dynamic impact at subballistic speeds by a novel impact test using sharpened tungsten carbide projectiles. The best performance against impact was achieved by an alumina with low glass content, relatively small mean grain size and which had been processed using cold isostatic pressing. The 
highest degree of plasticity without fracture was observed for samples with the highest glass content $(5 \%)$.

The macroscopic sub-surface cracking and surface radial cracks observed in these samples were modelled by combining the stress field caused by indentation of a blunt indenter (Hertzian equations) with a blister field which represented the observed plastic zone. The directions of the crack paths are determined by the plasticity of the material. However, a model which takes into account the pre-existing flaw distribution and microstructure of the material is required in order to fully explain the processes occurring in alumina materials subjected to dynamic impact.

\section{Acknowledgements}

We gratefully acknowledge Morgan Technical Ceramics for the provision of specimens of two of the materials studied in this work. This research is part of the Understanding and Improving Ceramic Armour (UNICAM) Project jointly funded by EPSRC and the Ministry of Defence, UK. We thank Richard Duffin, Stuart Carter, Dr Kalin Dragnevski, and Laurie Walton for their assistance with the experiments in this work.

\section{References}

[1] Walley SM. Historical review of high strain rate and shock properties of ceramics relevant to their application in armour. Adv Appl Ceram, 2010;109:446-66

[2] Viechnicki DJ, Slavin MJ, Kliman MI. Development and current status of armor ceramics. Am Ceram Soc Bull 1991;70:1035-9.

[3] Medvedovski E. Alumina ceramics for ballistic protection Part I. Am Ceram Soc Bull 2001;81:27-32. 
[4] Sujirote K, Dateraksa K, Chollacoop N. Practical requirements for alumina armor systems. Am Ceram Soc Bull 2007;86:20-5.

[5] Wilkins ML. Mechanics of penetration and perforation. International Journal of Engineering Science 1978;16:793-807.

[6] Chen WW, Rajendran AM, Song B, Nie X. Dynamic fracture of ceramics in armor applications. J Am Ceram Soc 2007;90:1005-18.

[7] Woodward RL, Gooch Jr WA, O’Donnell RG, Perciballi WJ, Baxter BJ, Pattie SD. A study of fragmentation in the ballistic impact of ceramics. International Journal of Impact Engineering 1994;15:605-18.

[8] O’Donnell RG. An investigation of the fragmentation behaviour of impacted ceramics. $J$ Mater Sci 1991;10:685-88.

[9] Luo H, Chen W. Dyanmic compressive response of intact and damaged AD995 alumina. Int J App Ceram Technol 2004;1:254-60.

[10] Chung S-K. Fracture characterization of armor ceramics. Am Ceram Soc Bull 1990;69:358-66.

[11] Anderson RM, Adler TA, Hawk JA. Scale of microstructure effects on the impact resistance of Al2O3. Wear 1993;162-164;1073-80.

[12] Lankford J. High strain rate compression and plastic flow of ceramics. J Am Ceram Soc 1981;64:C33-4.

[13] Lawn B, Wilshaw R. Review Indentation fracture: principles and applications. J Mater Sci 1975;10:1049-81.

[14] Munson DE, Lawrence RJ. Dynamic deformation of polycrystalline alumina. J App Phys 1979;50:6272-82.

[15] Bourne NK, Millett JCF, Chen M, McCauley JW, Dandekar DP. On the Hugoniot elastic limit in polycrystalline alumina. J App Phys 2007;102:073514. 
[16] Lankford J, Predebon WW, Staehler JM, Subhash G, Pletka BJ, Anderson CE. The role of plasticity as a limiting factor in the compressive failure of high strength ceramics. Mechanics of Materials 1998;29:205-18.

[17] Molis SE, Clarke DR. Measurement of stresses using fluorescence in an optical microprobe: stresses around indentations in a chromium-doped sapphire. J Am Ceram Soc 1990;73:3189-94.

[18] Wu HZ, Roberts SG, Derby B. Residual stress distributions around indentations and scratches in polycrystalline $\mathrm{Al} 2 \mathrm{O} 3$ and $\mathrm{Al} 2 \mathrm{O} 3 / \mathrm{SiC}$ nanocomposites measured using fluorescence probes. Acta Mater 2008;56:140-9.

[19] Guo S, Todd RI. Quantitative optical fluorescence microprobe measurements of stresses around indentations in $\mathrm{Al} 2 \mathrm{O} 3$ and $\mathrm{Al} 2 \mathrm{O} 3 / \mathrm{SiC}$ nanocomposites: The influence of depth resolution and specimen translucency Acta Mater 2010;59:2637-47.

[20] He J, Clarke DR. Determination of the piezospectroscopic coefficients for chromiumdoped sapphire. J Am Ceram Soc 1995;78:1347-53.

[21] Huber MT. Zur Theorie der Berührung fester elastischer Körper. Annalen der Physik 1904;43:61.

[22] Hertz H. On the contact of elastic solids. J Reine Angew Math 1891;92:156.

[23] Yoffe EH. Elastic stress fields caused by indenting brittle materials. Philos Mag 1982;40:617-28.

[24] Limpichaipanit A, Todd RI. The relationship between microstructure, fracture and abrasive wear in $\mathrm{Al} 2 \mathrm{O} 3 / \mathrm{SiC}$ nanocomposites and microcomposites containing 5 and $10 \%$ SiC. J Euro Ceram Soc 2009;29:2841-8.

[25] Feng G, Qu S, Huang Y, Nix WD. An analytical expression for the stress field around an elastoplastic indentation/contact. Acta Mater 2007;55:2929-38. 
[26] Tirupataiah Y, Sundararajan G. A dynamic indentation technique for the characterization of the high strain rate plastic flow behaviour of ductile metals and alloys. J Mech Phys Solids 1991;39: 243-71.

[27] Cook RF, Pharr GM. Direct observation and analysis of indentation cracking in glasses and ceramics. J Am Ceram Soc 1990;73:787-817.

[28] Fischer-Cripps AC. Predicting Hertzian fracture. J Mater Sci 1997;32:1277-83.

[29] Roesler FC. Brittle Fractures near Equilibrium. Proc Phys Soc Long 1956;B69:981.

[30] Marshall DB, Lawn BR, Evans AG. Elastic/Plastic indentation damage in ceramics: The lateral crack system. J Am Ceram Soc 1982;65:561-66. 
Tables

Table 1: Processing and Microstructural Properties of Samples

\begin{tabular}{|c|c|c|c|c|c|c|}
\hline Specimen & $\begin{array}{l}\text { Alumina } \\
\text { Powder }\end{array}$ & Preparation & $\begin{array}{l}\text { Glass } \\
\text { Content } \\
(\%)\end{array}$ & $\begin{array}{l}\text { Grain } \\
\text { Size } \\
(\mu \mathrm{m})\end{array}$ & $\begin{array}{l}\text { Density } \\
\left(\mathrm{g} / \mathrm{cm}^{3}\right)\end{array}$ & $\begin{array}{l}\text { Density } \\
\text { Relative to } \\
\text { Theoretical } \\
\text { Maximum } \\
(\%)\end{array}$ \\
\hline A & $\begin{array}{l}\text { TM- } \\
\text { DAR } \\
+\mathrm{MgO} \\
\end{array}$ & $\begin{array}{l}1550^{\circ} \mathrm{C} 2 \mathrm{~h} \\
\text { in air }\end{array}$ & 0 & 1.4 & 3.90 & 98.5 \\
\hline B & $\begin{array}{l}\text { TM- } \\
\text { DAR + } \\
\mathrm{MgO}\end{array}$ & $\begin{array}{l}1550^{\circ} \mathrm{C} 2 \mathrm{~h} \\
\text { in vacuum }\end{array}$ & 0 & 3.0 & 3.93 & 99.1 \\
\hline $\mathrm{C}$ & $\begin{array}{l}\text { TM- } \\
\text { DAR }\end{array}$ & $\begin{array}{l}1550^{\circ} \mathrm{C} 2 \mathrm{~h} \\
\text { in air }\end{array}$ & 0 & 6.8 & 3.95 & 99.7 \\
\hline $\mathrm{D}$ & - & - & 5 & 8.3 & 3.89 & - \\
\hline $\mathrm{E}$ & - & - & 2 & 4.7 & 3.76 & - \\
\hline $\mathrm{F}$ & AES11C & $\begin{array}{l}1550^{\circ} \mathrm{C} 2 \mathrm{~h} \\
\text { in air, CIPed }\end{array}$ & 0 & 2.0 & 3.92 & 99.0 \\
\hline
\end{tabular}

Table 2: Performance ranking of alumina specimens under impact

\begin{tabular}{llllll}
\hline Rank & Specimen & Radial Cracks & CIPed & $\begin{array}{l}\text { Grain } \\
\text { Size }(\mu \mathrm{m})\end{array}$ & $\begin{array}{l}\text { Glass content } \\
(\boldsymbol{\%})\end{array}$ \\
\hline 1 & $\mathrm{~F}$ & None observed & $\mathrm{Y}$ & 2.0 & 0 \\
\hline$=2$ & $\mathrm{~A}$ & $\begin{array}{l}\sim 5, \text { no complete } \\
\text { fractures }\end{array}$ & $\mathrm{N}$ & 1.4 & 0 \\
\hline$=2$ & $\mathrm{~B}$ & $\begin{array}{l}\sim 5, \text { no complete } \\
\text { fractures }\end{array}$ & $\mathrm{N}$ & 3.0 & 0 \\
\hline$=2$ & $\mathrm{C}$ & $\begin{array}{l}\sim 5, \text { no complete } \\
\text { fractures }\end{array}$ & $\mathrm{N}$ & 6.9 & 0 \\
\hline 3 & $\mathrm{E}$ & $\begin{array}{l}\sim 5,1 \text { complete } \\
\text { fracture }\end{array}$ & - & 4.7 & 2 \\
\hline 4 & $\mathrm{D}$ & $\begin{array}{l}\sim 7,1 \text { complete } \\
\text { fracture }\end{array}$ & - & 8.3 & 5 \\
\hline
\end{tabular}




\section{Figures}

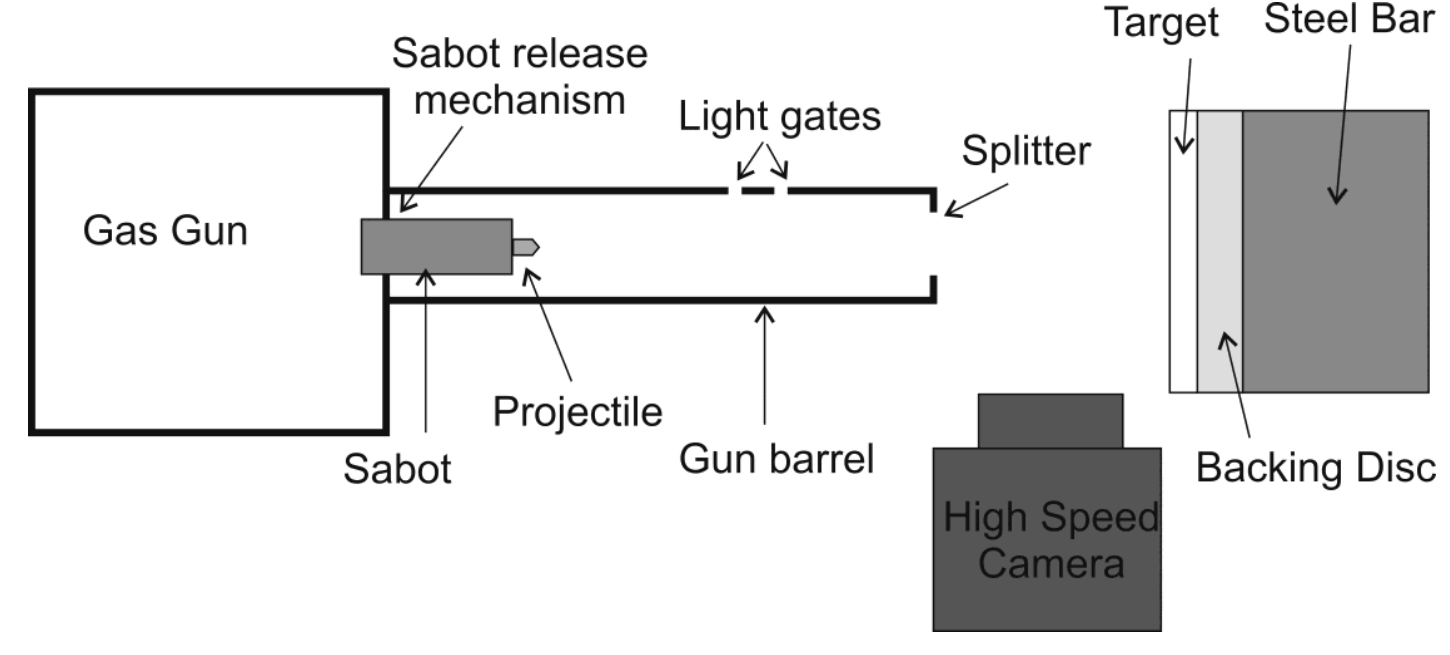

Figure 1: Dynamic impact test setup.

a)

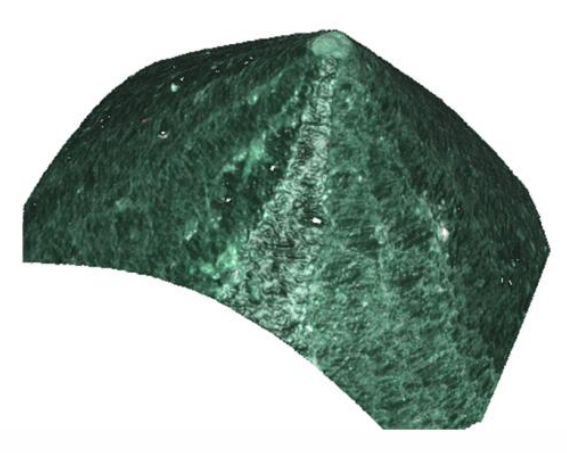

b)

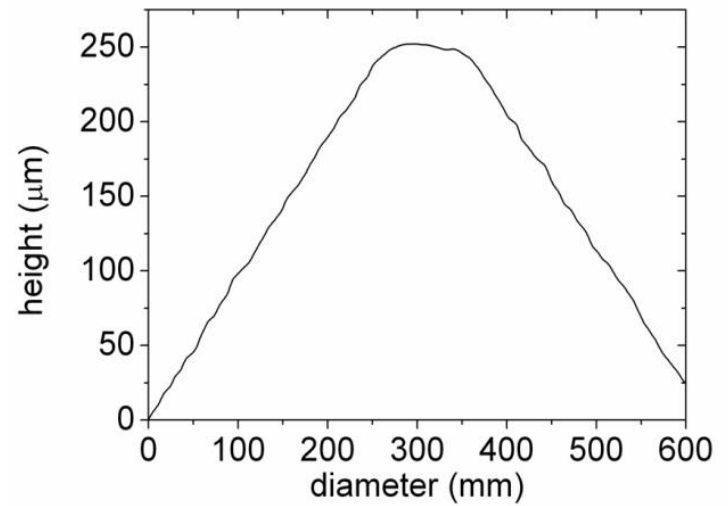

Figure 2 a) 3D optical microscope image of projectile tip before impact testing. b) Linescan showing the width of the blunt region for this projectile. 


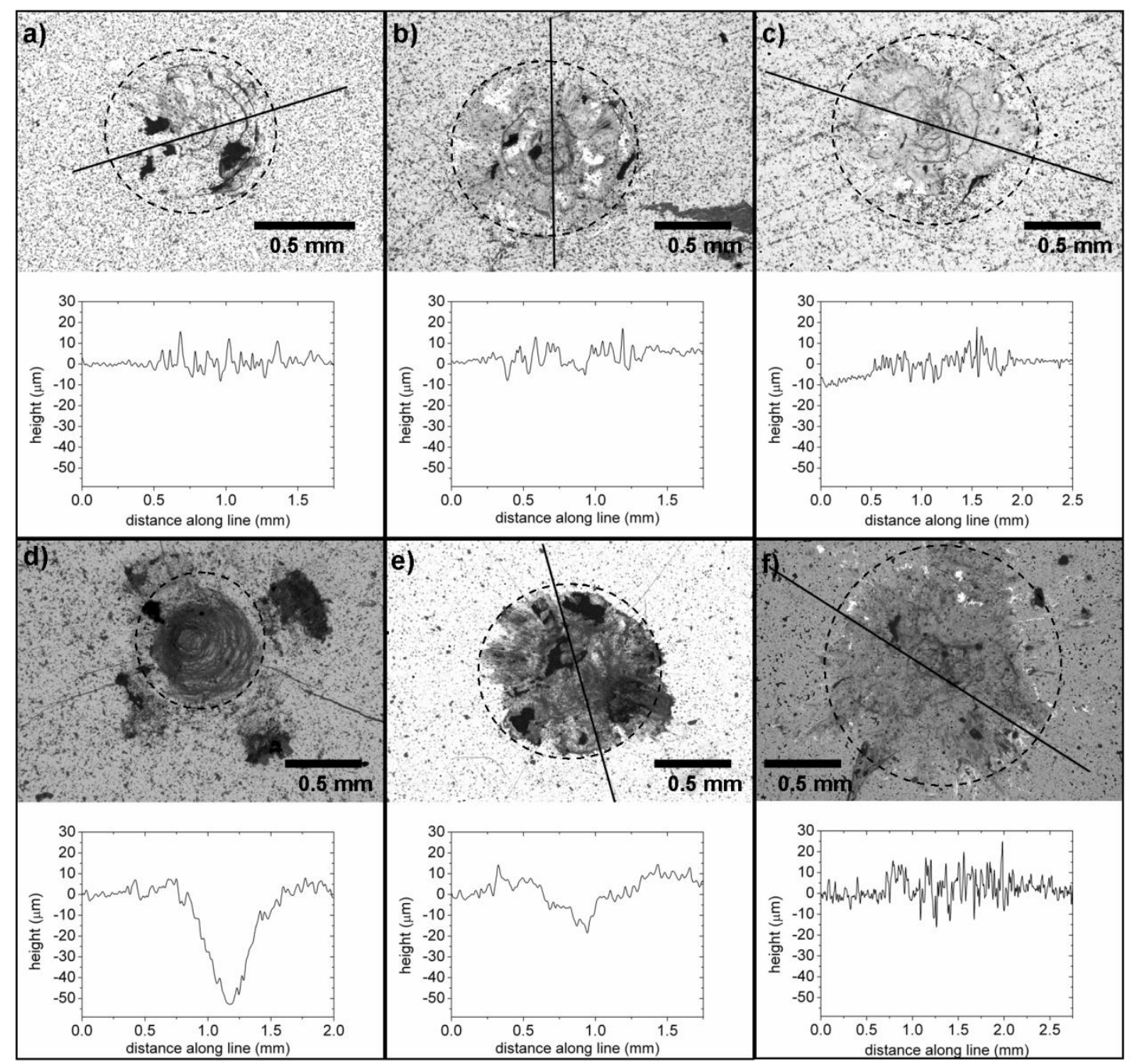

Figure 3: 3D optical microscopy images showing the size and shape of indentations. The image shows a 2D projection of the 3D image of each indent while the linescan shows the depth of the indentation along the line sketched on the image. The dotted circles indicate the surface micro-cracked region in each sample. a) A, b) B, c) C, d) D, e) E, f) F. 


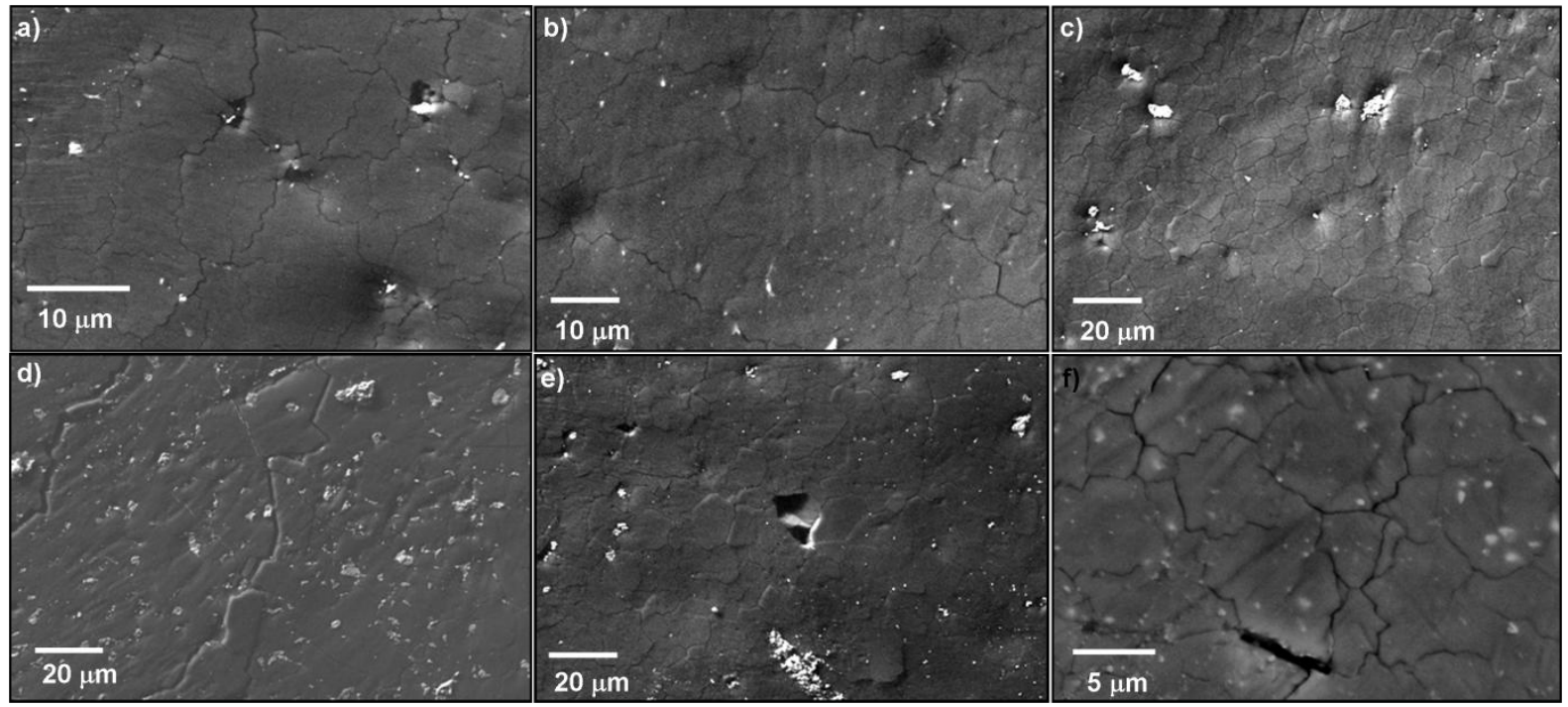

Figure 4: SEM micrographs showing micro-cracking present in all specimens. a) A, b) B, c) C, d) D e) E f) F.

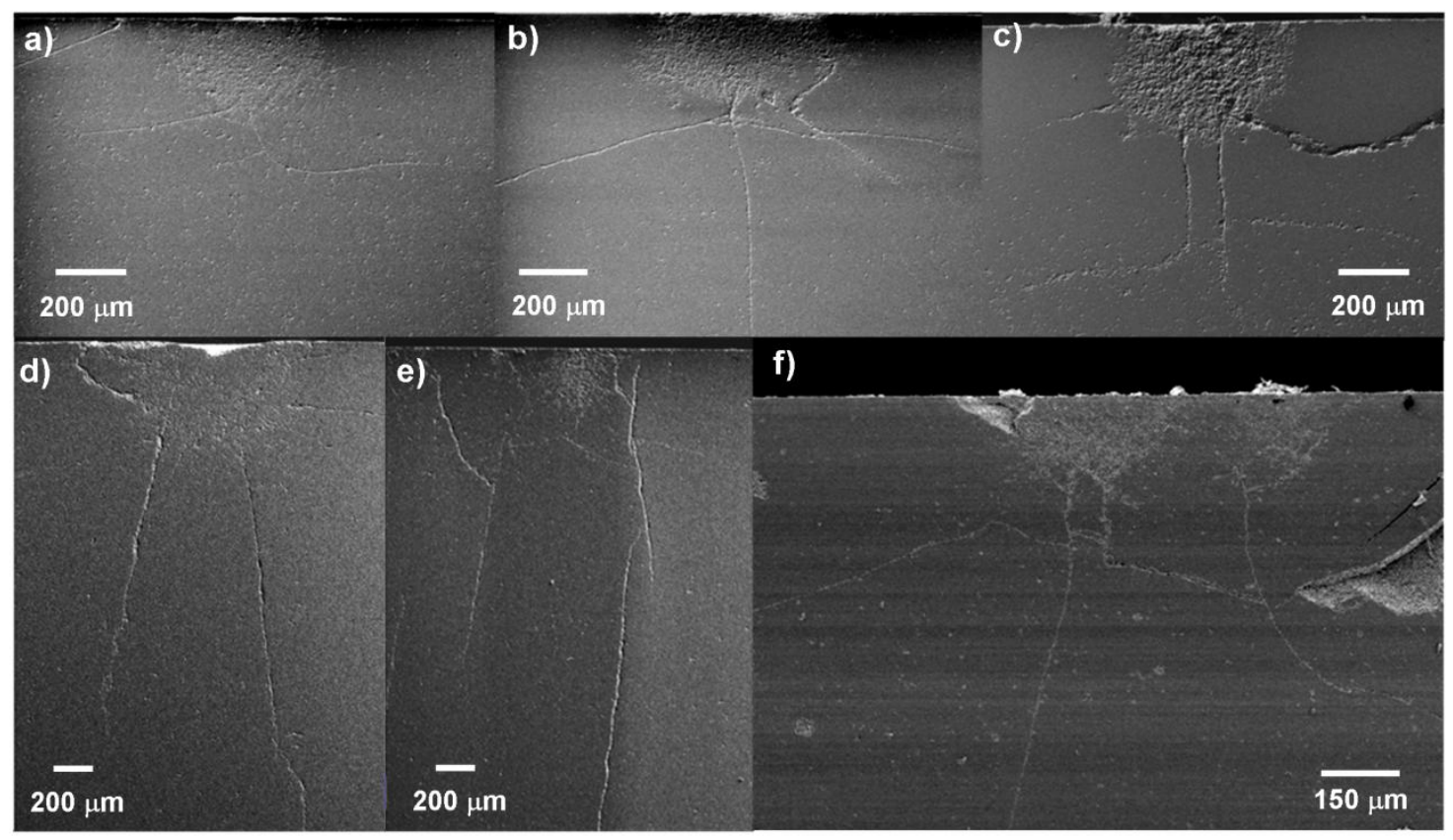

Figure 5: SEM micrographs of cross-sections through the impact site of typical specimens a) A, b) B, c) C, d) D, e) E, f) F. Note that the magnification is not the same for all images. 

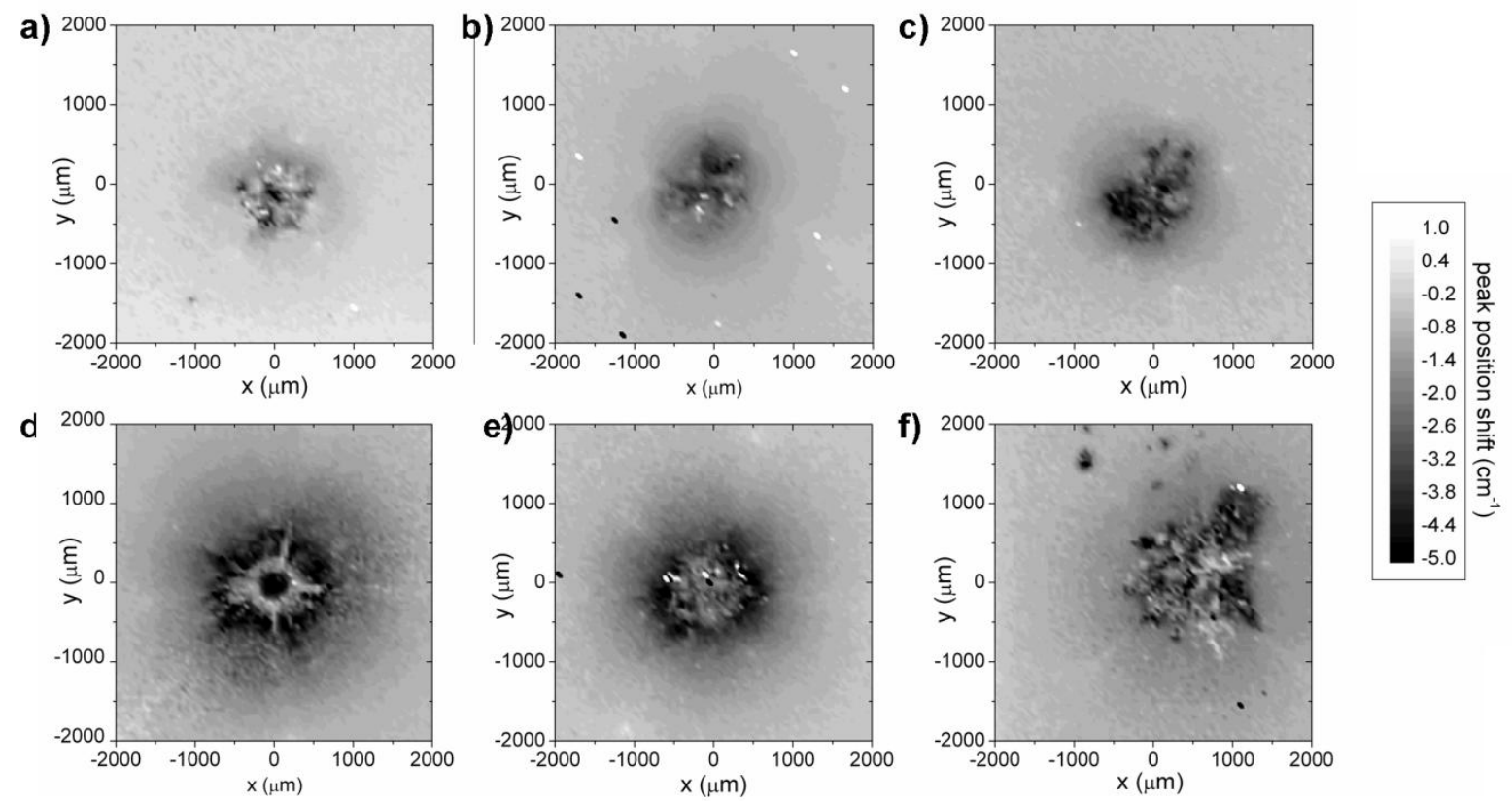

Figure 6: Representative $\mathrm{Cr}^{3+} \mathrm{R} 1$ fluorescence peak shift maps for alumina specimens studied in this work, mapping the indented region of the facing surface of the specimen in each case. a) A, b) B, c) C, d) D e) E f) F.
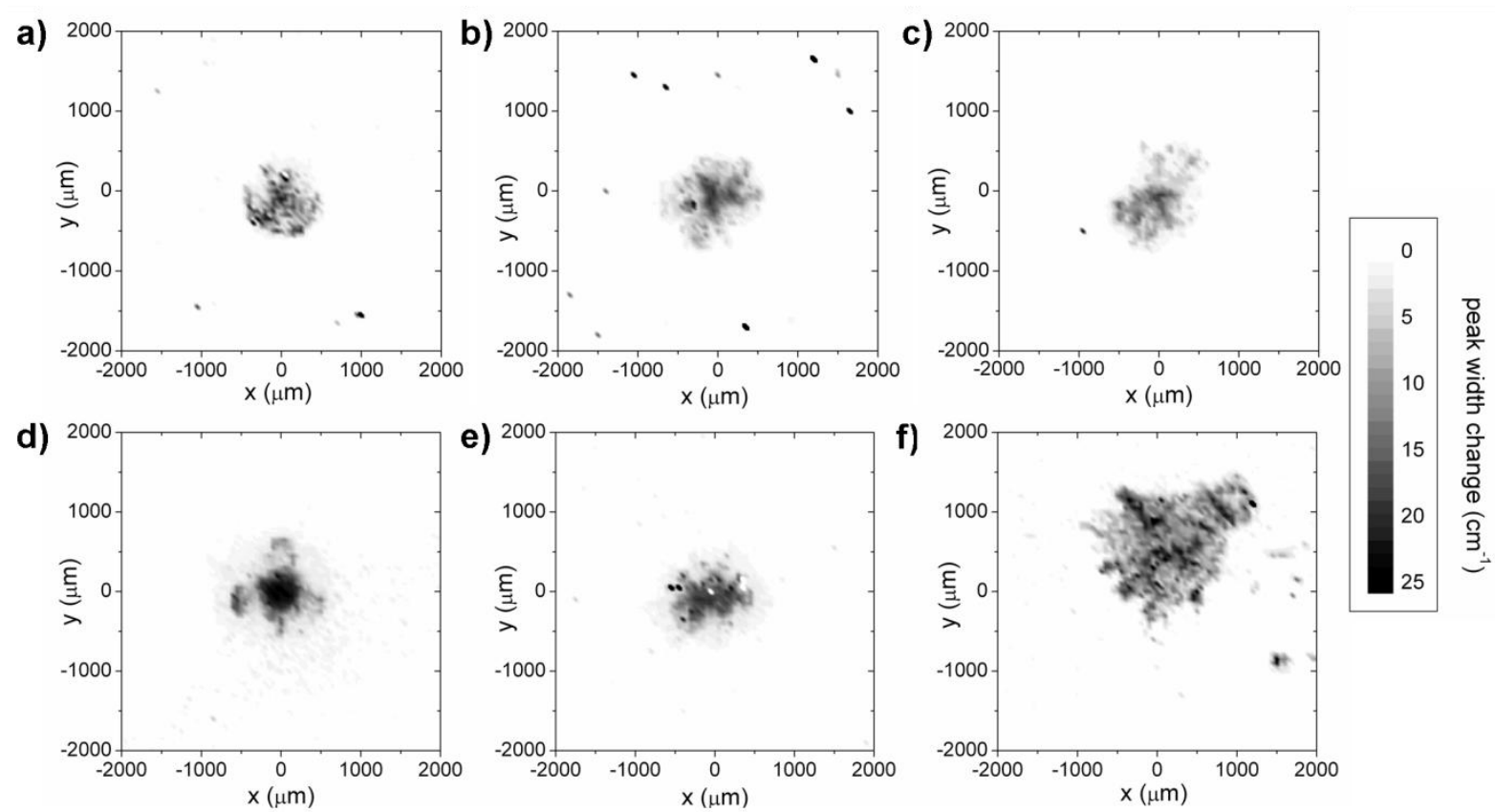

Figure 7: Representative $\mathrm{Cr}^{3+} \mathrm{R} 1$ fluorescence peak width maps for alumina specimens, mapping the indented region of the facing surface of the specimen in each case. a) A, b) B, c) C, d) D e) E f) F. 

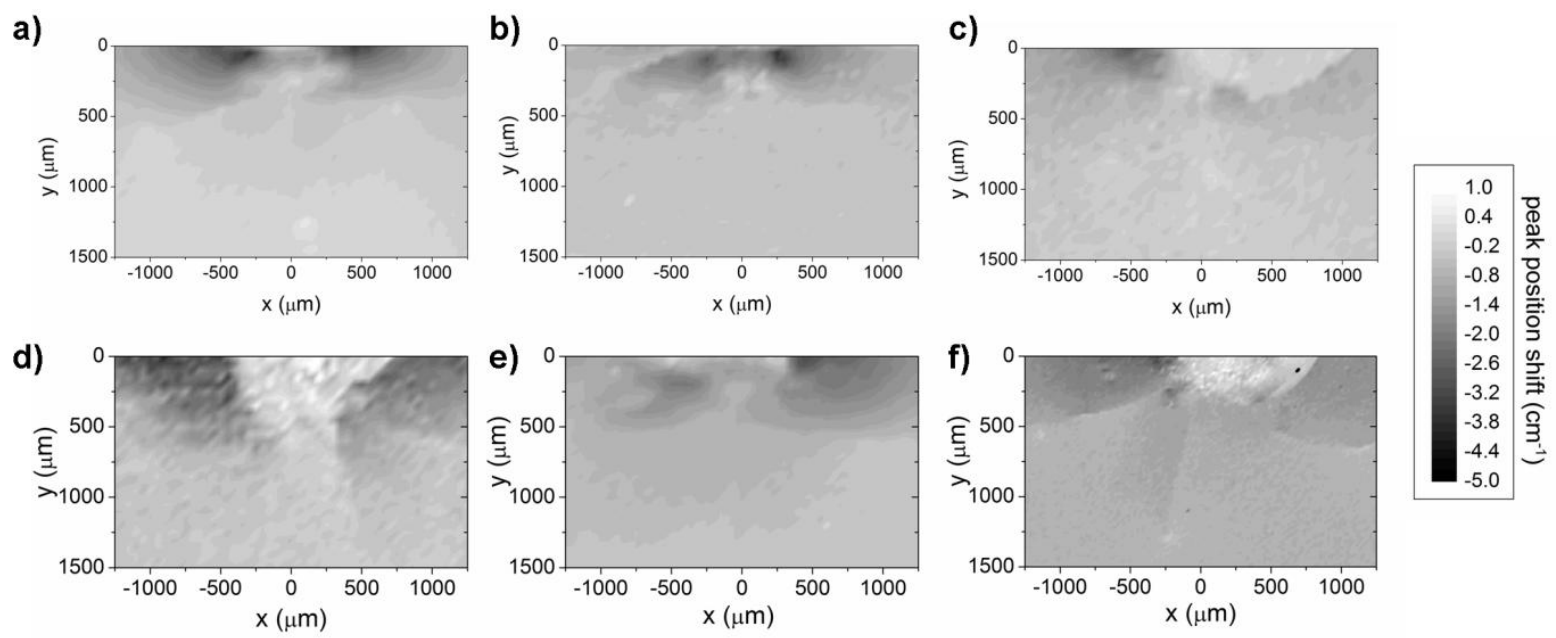

Figure 8: Representative $\mathrm{Cr}^{3+} \mathrm{R} 1$ fluorescence peak shift maps for alumina specimens, mapping the cross-section of the region below the indent for the specimen in each case. Maps are all oriented with the top surface at the top of the image. a) A, b) B, c) C, d) D e) E f) F.
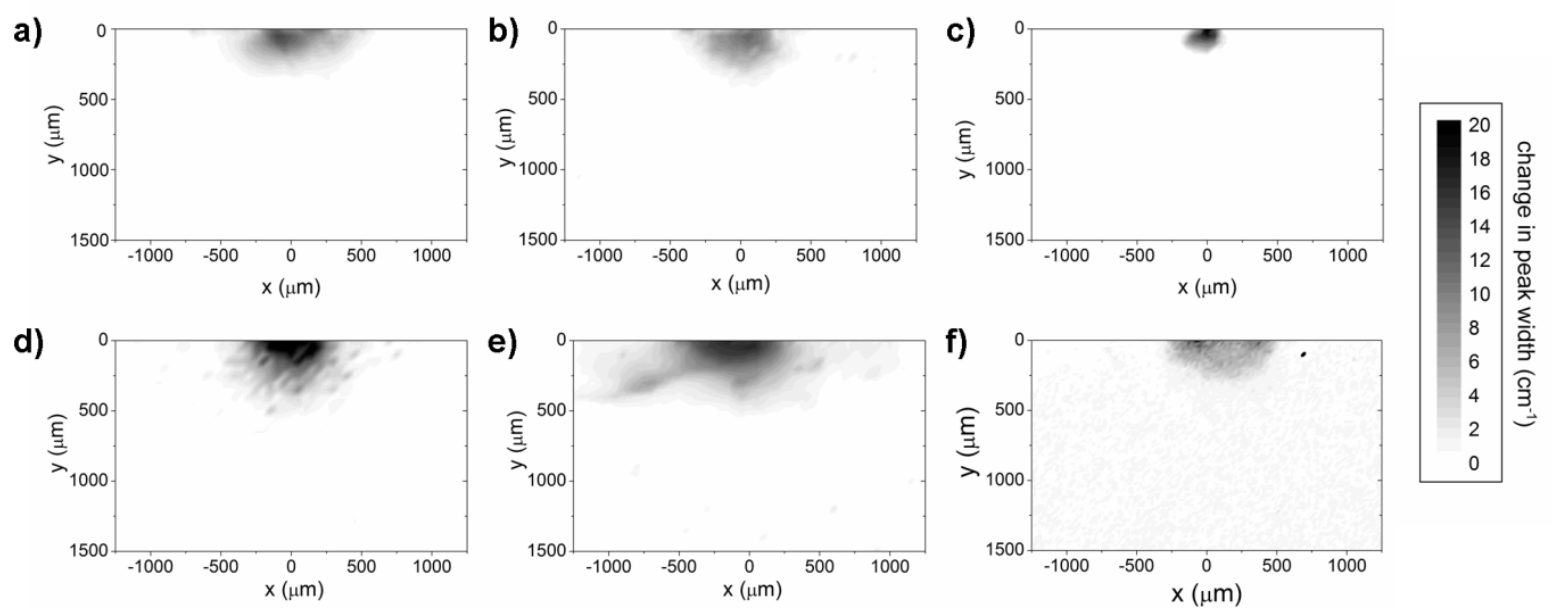

Figure 9: Representative $\mathrm{Cr}^{3+}$ fluorescence peak width maps for alumina specimens, mapping the cross-section of the region below the indent for the specimen in each case. Maps are all oriented with the top surface at the top of the image. a) A, b) B, c) C, d) D e) E f) F. 

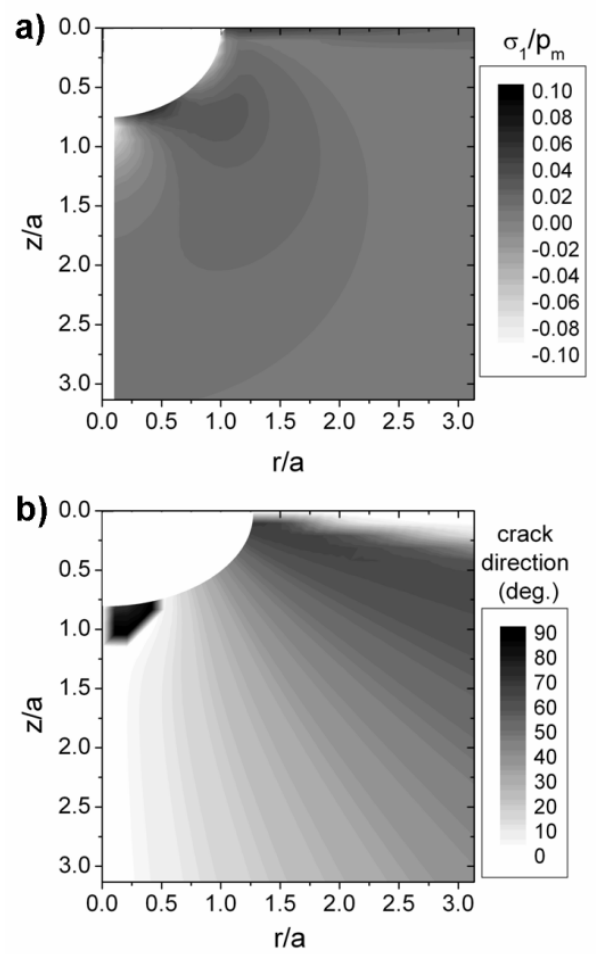

Figure 10: (a) Magnitude and (b) direction of the maximum principal stress $\sigma_{1}$ in the $r-z$ plane for $B / P=0.03 \mathrm{~m}^{-3}$, with the axes normalised by the contact radius $a$ and the stress normalised by the mean contact pressure $p_{m}$. The equations are not valid for the plastic zone itself so this region has been removed by estimating the size and shape of the plastic zone from the $\mathrm{Cr}^{3+}$ fluorescence peak broadening maps (Fig. 7 and 9). 